\title{
Functional Analysis of a Multicopy Host-Selective ACT-Toxin Biosynthesis Gene in the Tangerine Pathotype of Alternaria alternata Using RNA Silencing
}

\author{
Y. Miyamoto, ${ }^{1}$ A. Masunaka, ${ }^{1}$ T. Tsuge, ${ }^{2}$ M. Yamamoto, ${ }^{3}$ K. Ohtani, ${ }^{1}$ T. Fukumoto, ${ }^{1}$ K. Gomi, ${ }^{1}$ T. L. Peever, ${ }^{4}$ \\ and K. Akimitsu ${ }^{1}$ \\ ${ }^{1}$ United Graduate School and Faculty of Agriculture, Kagawa University, Miki, Kagawa 761-0795, Japan; ${ }^{2}$ Graduate School \\ of Bioagricultural Sciences, Nagoya University, Nagoya 464-8601, Japan; ${ }^{3}$ Faculty of Agriculture, Okayama University, \\ Okayama 700-8530, Japan; ${ }^{4}$ Department of Plant Pathology, Washington State University, Pullman, WA 99164-6430, U.S.A. \\ Submitted 5 June 2008. Accepted 6 August 2008.
}

\begin{abstract}
Alternaria brown spot, caused by the tangerine pathotype of Alternaria alternata, is a serious disease of commercially important tangerines and their hybrids. The pathogen produces host-selective ACT toxin, and several genes (named $A C T T$ ) responsible for ACT-toxin biosynthesis have been identified. These genes have many paralogs, which are clustered on a small, conditionally dispensable chromosome, making it difficult to disrupt entire functional copies of $A C T T$ genes using homologous recombination-mediated gene disruption. To overcome this problem, we attempted to use RNA silencing, which has never been employed in Alternaria spp., to knock down the functional copies of one $A C T T$ gene with a single silencing event. ACTT2, which encodes a putative hydrolase and is present in multiple copies in the genome, was silenced by transforming the fungus with a plasmid construct expressing hairpin ACTT2 RNAs. The ACTT2 RNA-silenced transformant (S-7-24-2) completely lost $A C T T 2$ transcripts and ACT-toxin production as well as pathogenicity. These results indicated that RNA silencing may be a useful technique for studying the role of $A C T T$ genes responsible for host-selective toxin biosynthesis in $A$. alternata. Further, this technique may be broadly applicable to the analysis of many genes present in multiple copies in fungal genomes that are difficult to analyze using recombination-mediated knockdowns.
\end{abstract}

The plant-pathogenic fungus Alternaria alternata has several biological variants that produce distinct host-selective toxins (HST) (Kohmoto and Otani 1991; Nishimura and Kohmoto 1983). HST are low-molecular weight secondary metabolites with toxicity toward distinct plant genotypes and have the same specificity as infection by the toxin-producing pathogen (Nishimura and Kohmoto 1983; Scheffer and Livingston 1984; Walton 1996; Wolpert et al. 2003; Yoder 1980).

The tangerine pathotype of A. alternata causes Alternaria brown spot disease, which affects many tangerines and their hybrids. Pathogenesis is thought to be due to the ability of the fungus to produce the host-selective ACT toxin (Akimitsu et al. 2003; Kohmoto and Otani 1991; Kohmoto et al. 1979;

Current address for A. Masunaka: National Agricultural Research Center for Hokkaido Region, Hokkaido 082-0071, Japan.

Corresponding author: Kazuya Akimitsu; Telephone: +81-87-891-3131; Fax: +81-87-891-3021; E-mail: kazuya@ ag.kagawa-u.ac.jp
1991). Toxin at a concentration of $2 \times 10^{-8} \mathrm{M}$ causes veinal necrosis on leaves, with a rapid loss of electrolytes from host cells (Kohmoto and Otani 1991; Kohmoto et al. 1991, 1993). The mode of action of ACT toxin appears to be complex, but ultrastructural changes in cells treated with the toxin indicated that the primary site of action is likely the plasma membrane (Kohmoto et al. 1993).

The major form of HST produced by the tangerine pathotype was designated ACT-toxin I (Fig. 1) (Kohmoto et al. 1993). ACT-toxin I and its derivatives are the only major products detected in fluids purified from germinating conidia (Kohmoto et al. 1993). The structure of ACT toxin is related to that of AK- and AF-toxin, which are the HST produced by the Japanese pear and strawberry pathotypes of A. alternata, respectively (Fig. 1) (Kohmoto et al. 1993; Nakashima et al. 1985; Nakatsuka et al. 1986). These toxins share a common 9,10epoxy-8-hydroxy-9-methyl-decatrienoic acid moiety (Fig. 1) (Kohmoto et al. 1993; Nakashima et al. 1985; Nakatsuka et al. 1986).

We previously identified $A C T T 1$ and ACTT2 from the tangerine pathotype, which were expected to participate in the biosynthesis of the common moiety in the structures of ACT-, AK-, and AF-toxins (Kohmoto et al. 1993; Masunaka et al. 2000, 2005; Nakashima et al. 1985; Nakatsuka et al. 1986; Tanaka et al. 1999). Both ACTT1 and ACTT2 locate to a single small chromosome of the tangerine pathotype, with a size of 1.1 to $1.9 \mathrm{Mb}$ that varied in different field isolates (Masunaka et al. 2005). Disruption of $A K T 1$ in the Japanese pear pathotype, similar to ACTT1 at the nucleotide level (90.6\%), led to a loss of production of AK toxin as well as loss of decatrienoic acid (Masunaka et al. 2000; Tanaka et al. 1999). Southern blot analysis indicated that ACTT2 exists as multiple copies in the genome of the tangerine pathotype (Masunaka et al. 2000; 2005). It has been difficult to disrupt entire functional copies of ACTT genes using homologous recombination-mediated gene disruption, due to redundancy, lack of selectable markers for multiple transformations with different vector constructs, as well as low efficiency of homologous recombination.

In this study, we attempted to use RNA silencing technology to knock down the function of ACTT genes, thus overcoming some of the limitations of gene knockouts using homologous recombination-mediated gene disruption. RNA silencing, initially reported in Caenorhabditis elegans (Fire et al. 1998), is a posttranscriptional gene silencing phenomenon induced by double-stranded RNA (dsRNA). In many organisms, dsRNA is cleaved by Dicer, a nuclease of the RNase III family, into 
small interfering RNAs (siRNA) that are then incorporated into a ribonucleoprotein complex (RNA-induced silencing complex [RISC]) (Bernstein et al. 2001; Hammond et al. 2001). RISC recognizes and degrades homologous mRNAs by complementary base pairing with the incorporated siRNA (Elbashir et al. 2001; Zamore et al. 2000). This gene-silencing system has also provided powerful reverse genetic tools for functional genomics in various filamentous fungi, including Neurospora crassa (Cogoni et al. 1996; Romano and Macino 1992), Magnaporthe oryzae (Kadotani et al. 2003), Colletotrichum lagenarium (Nakayashiki et al. 2005), Venturia inaequalis (Fitzgerald et al. 2004), Phytophthora infestans (van West et al. 1999), Bipolaris oryzae (Moriwaki et al. 2007), Fusarium graminearum (McDonald et al. 2005), and some of the Aspergillus spp. (Table 1) (Hammond and Keller 2005; Mouyna et al. 2004; Yamada et al. 2007). Although the potential use of this technique for analysis of fungal gene function in molecular plant-microbe interactions has been suggested, we are aware of only one instance in which it has been used to analyze fungal-plant interactions. The Fusarium graminearum silencing mutant tri6 with reduced mycotoxin (deoxynivalenol

\section{ACT toxin}

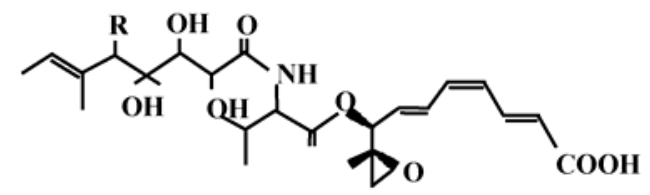

ACT-toxin I: $\mathbf{R}=\mathbf{O H}$

ACT-toxin II: $\mathbf{R}=\mathbf{H}$

AK toxin

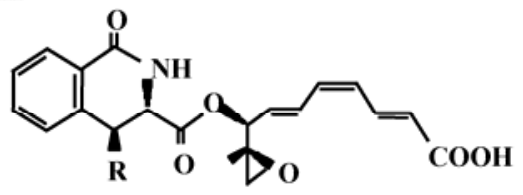

AK-toxin I: $\mathbf{R}=\mathrm{CH}_{3}$ AK-toxin II: $\mathbf{R}=\mathbf{H}$

AF toxin

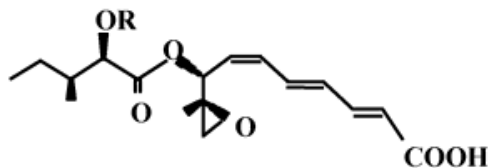

AF-toxin I: $\quad \mathrm{R}=\mathrm{COCH}(\mathrm{OH}) \mathrm{C}\left(\mathrm{CH}_{3}\right)_{2} \mathrm{OH}$ AF-toxin II: $\mathbf{R}=\mathbf{H}$ AF-toxin III: $\mathrm{R}=\mathrm{COCH}(\mathrm{OH}) \mathrm{CH}\left(\mathrm{CH}_{3}\right)_{2}$

Fig. 1. Chemical structures of ACT, AK, and AF toxins produced by the tangerine, Japanese pear, and strawberry pathotypes of Alternaria alternata (Kohmoto et al. 1993; Nakashima et al. 1985; Nakatsuka et al. 1986).
[DON]) production showed a reduction in virulence in a head blight assay (McDonald et al. 2005), providing evidence for DON as a virulence factor in this pathosystem.

RNA silencing has never been demonstrated in Alternaria spp., so we first designed a vector construct for generating hairpin RNA of the green fluorescent protein $(G F P)$ gene in $A$. alternata. We then introduced the vector into a mutant strain of A. alternata causing citrus black rot (Isshiki et al. 2003), which overexpressed GFP as the silencing target, to determine if gene silencing could function in A. alternata. After this preliminary demonstration of RNA-silencing efficiency, we analyzed the role of ACTT2 in ACT-toxin biosynthesis. ACTT2 has multiple functional copies with high sequence identity in the genome of the A. alternata tangerine pathotype, which were silenced by introduction of a vector that generated ACTT2 hairpin RNA.

\section{RESULTS}

Presence of multiple $A C T T 2$ copies in the genome of the tangerine pathotype of A. alternata.

One of the previously identified ACTT genes, ACTT2 (accession AB432914), encodes a putative hydrolase (Masunaka et al. 2000) that is considered to play a role in the biosynthesis of the 9,10-epoxy-8-hydroxy-9-methyl-decatrienoic acid moiety of ACT toxin (Fig. 1) (Masunaka et al. 2000, 2005; Tanaka et al. 1999). Pulsed-field gel electrophoresis (PFGE) and Southern blotting demonstrated that ACTT2 locates to a single chromosome of 1.9 to $2.0 \mathrm{Mb}$, varying in different field isolates of ACTtoxin producers, but not to chromosomes from any other pathotype or nonpathogenic species of genus Alternaria (Fig. 2).

The distribution of ACTT2 in the genome of strain $\mathrm{SH} 20$ was further examined by genomic Southern blotting (Fig. 3). The hybridization pattern of the ACTT2 probe was complicated, and three to five fragments were detected with the probe following digestion by several restriction enzymes (Fig. 3). Expected sizes of bands have been confirmed, such as a $1.4-\mathrm{kb}$ fragment digested with $B a m \mathrm{HI}$, that recognize a single restriction site within the sequenced region of ACTT2 (Masunaka et al. 2000), as well as fragments of $3.7 \mathrm{~kb}$ digested with $B g l \mathrm{I}$, $9.8 \mathrm{~kb}$ with EcoRI, and $10.1 \mathrm{~kb}$ with SalI, which recognize no restriction site within the sequence (Fig. 3B). However, detection of many unexpected sizes of bands based on the restriction map of pcCL4-1 (Fig. 3) indicate the presence of additional ACTT2 copies with different restriction sites in the franking or open reading frame (ORF) region.

\section{Examination of RNA-silencing efficiency} in Alternaria spp. using the GFP gene as the target.

To establish a model system for elucidating RNA silencing in Alternaria spp., we attempted to silence GFP gene expression in the citrus black rot strain G1 of A. alternata, which constitutively expresses GFP (Isshiki et al. 2003). We constructed a plasmid vector pASY-GFP to make hairpin $G F P$

Table 1. Phytopathogenic fungi used for RNA-silencing studies

\begin{tabular}{|c|c|c|c|}
\hline Fungi & Target gene of RNA silencing & Role $^{\mathbf{a}}$ & Reference \\
\hline Phytophthora infestans & inf1 (elicitor protein) & ND & van West et al. 1999 \\
\hline Magnaporthe oryzae & $\mathrm{GFP}^{\mathrm{b}}, M P G 1$ (hydrophobin, polyketide synthase-like gene) & ND & Nakayashiki et al. 2005 \\
\hline Venturia inaequalis & GFP, $T H N$ (trihydroxynaphthalene reductase) & ND & Fitzgerald et al. 2004 \\
\hline Colletotrichum lagenarium & GFP & ND & Nakayashiki et al. 2005 \\
\hline Aspergillus flavus & aflR (transcription factor for mycotoxin biosynthesis) & ND & McDonald et al. 2005 \\
\hline Aspergillus parasiticus & aflR (transcription factor for mycotoxin biosynthesis) & ND & McDonald et al. 2005 \\
\hline Fusarium graminearum & tri6 (DNA-binding protein for mycotoxin biosynthesis) & Virulence reduced & McDonald et al. 2005 \\
\hline Bipolaris oryzae & PKS1 (polyketide synthase) & ND & Moriwaki et al. 2007 \\
\hline
\end{tabular}

${ }^{a}$ Role of the target gene in pathogenesis. ND means not determined.

${ }^{\mathrm{b}} \mathrm{GFP}=$ green fluorescent protein. 
RNAs with sense and antisense sequences of GFP (720 bp) that formed a double-stranded structure at the stem (Fig. 4), and pASY-GFP was cotransformed into the GFP-expressing transformant of G1 with pII99 (Namiki et al. 2001) carrying NPTII as the selectable marker. Geneticin-resistant transformants $(n=100)$ were randomly selected, and the intensity of GFP fluorescence was measured microscopically with an image analyzer. Transformants were classified into three categories based on relative fluorescent intensity compared with G1. Ninety-five transformants had equal intensity to those of transformants 8-1 and 13-2 (Fig. 5), representing an approximately 85 to $90 \%$ reduction in fluorescence intensity relative to that of wild type. Transformants 9-1, 9-2, and 11 showed greater reduction (more than 95\%) in intensity of fluorescence, and two transformants 2-1 and 2-2 lost GFP expression completely (Fig. 5).

For transformants 2-1 and 2-2 with no visible fluorescence, the integration of pASY-GFP was analyzed by polymerase chain reaction (PCR). The primer set of PacCITF1multisite and GFPR1 was used for detection of PCR products corresponding to the hairpin head and sense part of the dsRNA region from genomic DNA of the transformants (Fig. 6A). PCR products with the expected size of 841 bp were amplified from all transformants but not from the original strain used for GFP transformation (Fig. 6A). Accumulation of GFP mRNA was reduced in the transformants, and no visible transcript was observed in transformants 2-1 and 2-2 (Fig. 6B). The presence of siRNA was also confirmed by Northern blots using both sense and antisense probes using one (2-2) of the transformants showing no visible GFP fluorescence and transcripts (Fig. 6C). Statistical analysis by a Tukey-Kramer test showed no differences in growth rate of cultures, sporulation, and spore germination found between the wild type, GFP-expressing transformant (G1) and the GFP RNA-silenced transformants.

\section{Use of RNA silencing for functional disruption of $\boldsymbol{A C T T 2}$.}

Once the efficiency of RNA silencing had been established using GFP in Alternaria spp., we applied this method to knock down the function of $A C T T 2$ in the tangerine pathotype of $A$. alternata. The RNA silencing vector pASYII-ACTT2 express-

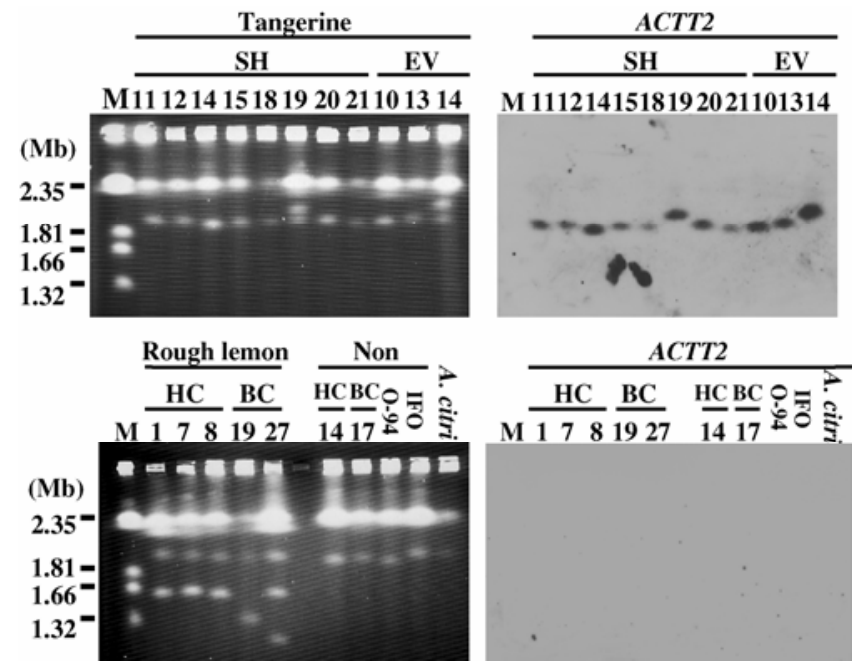

Fig. 2. Distribution of $A C T T 2$ among chromosomes in the tangerine and rough lemon pathotypes and saprophytic strains of Alternaria alternata. Intact chromosomal DNAs of each isolate were separated with pulsedfield gel electrophoresis ( $0.8 \%$ agarose gel) under conditions optimized for separation of chromosomes $<2.0 \mathrm{Mb}$ (left panel). Chromosomes were transferred onto nylon membrane, and ACTT2 sequences were detected with digoxigenin-labeled ACTT2 probes (right panel). Sizes (in Mb) of Hansenula wingei chromosomes are indicated at the left.


Fig. 3. Genomic Southern blot analysis of ACTT2 sequences in the tangerine pathotype strain $\mathrm{SH} 20$, using several restriction enzymes. DNA of strain SH20 digested with PstI (lane P), SacI (Sc), HindIII (H), XbaI (Xb), XhoI (Xh), SalI (Sl), BanIII (Bn), BglI (Bg), EcoRI (E), and BamHI (Bm). Sizes of marker DNA fragments (HindIII-digested $\lambda$ DNA) are indicated at left.

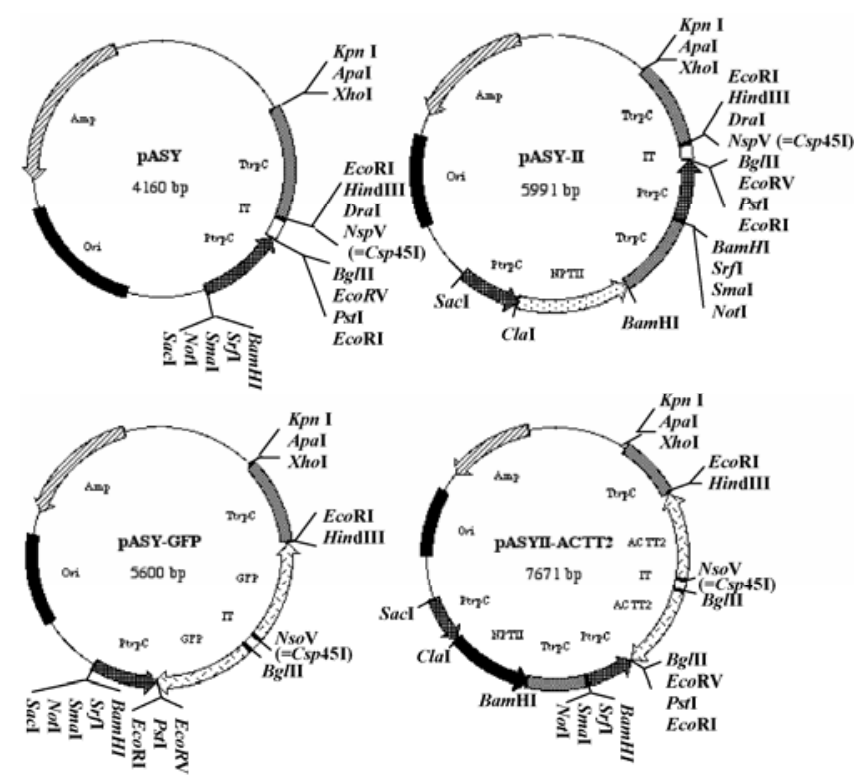

Fig. 4. Construction and plasmid maps of RNA-silencing vectors pASY, pASY-II, pASY-GFP, and pASYII-ACTT2. 
ing hairpin ACTT2 RNA, constructed by sense and antisense sequences of ACTT2 (780 bp) in pASY-II carrying NPTII as the selection marker (Fig. 4), was transformed into the strain SH20 A. alternata tangerine pathotype. A total of 75 transformants were examined for production of ACT toxin in the culture filtrates using a leaf necrosis assay, and 21 transformants showing less than 50\% necrosis development compared with that caused by the wild-type $\mathrm{SH} 20$ in toxin-sensitive citrus leaves were selected. These transformants were further examined for loss of pathogenicity in a spray-inoculation assay on tangerine leaves and ability to produce ACT toxin detected by high-pressure liquid chromatography (HPLC). Two transformants, S-7-3 and S-7-24-2, were selected. Transformants carrying pASYII-ACTT2 were selected by resistance to geneticin and PCR amplification of the vector-specific region (Fig. 7A). Transcript accumulation of ACTT2 was detectable by reverse transcription (RT)-PCR but was significantly reduced in S-7-3 compared with that of wild-type SH20 (Fig. 7B). HPLC analysis of extracts from culture filtrates of S-7-3 indicated that the peak area of S-7-3 showed $84.6 \%$ reduction compared with that of the wild type (Fig. 7C). An additional two transformants showed similar reduction to that of S-7-3, and another 17 transformants also showed 20 to $30 \%$ reduction in ACTtoxin production compared with wild type. RT-PCR of transformant S-7-24-2 showed no detectable ACTT2 transcript, and no peak of ACT toxin was detected by HPLC analysis (Fig. 7B and $\mathrm{C}$ ). Leaves sprayed with conidia of the wild type were covered by necrotic brown lesions $48 \mathrm{~h}$ postinoculation, while those sprayed with conidia of S-7-3 showed significant reduction in the numbers of lesions, and no lesions were observed on leaves sprayed with conidia of S-7-24-2 (Fig. 7D). Statistic analysis by Tukey-Kramer test showed no differences in growth rate of cultures, sporulation, and spore germination found between wild type and the ACTT2 RNA silenced transformants.

\section{DISCUSSION}

Most of the HST biosynthesis genes in A. alternata are present in multiple functional copies with high sequence identity among paralogs. This creates challenges for gene manipulations that are required to demonstrate a causal connection between each of the genes and a phenotype. Repeated rounds of disruption are required to knock out all copies of a particular target gene. Each round of disruption needs an independent vector construct with a different antibiotic resistance marker; however, only a few such resistance genes are available for fungi, and low efficiency of homologous recombination in Alternaria spp. also limits the effectiveness of the approach. To solve these limitations, RNA silencing was applied to ACTT2, which has the highest number of copies among the putative ACT-toxin biosynthetic ACTT genes identified in the genome of the tangerine pathotype.

In this study, the occurrence of RNA silencing was initially demonstrated using GFP as the monitoring marker. The degree of suppression of GFP fluorescence varied significantly among transformants using the vector construct designed for generating a hairpin GFP RNA. All transformants examined (100) showed more than $85 \%$ reduction in fluorescence, including three $(9-1,9-2,11)$ transformants reduced more than $95 \%$ and
G1
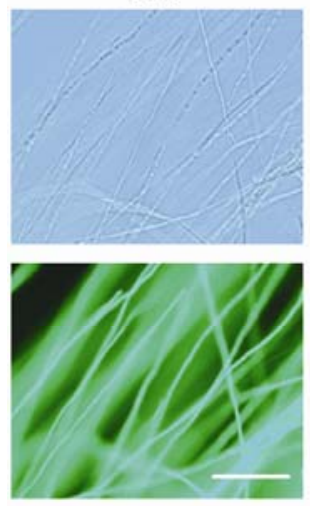

9-1


$2-1$
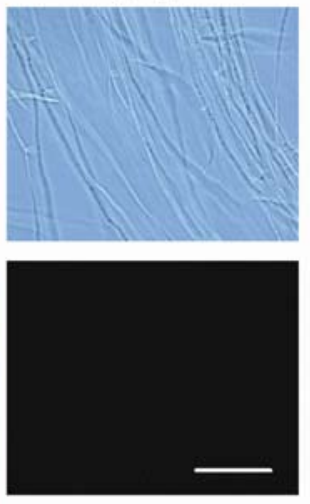

9-2
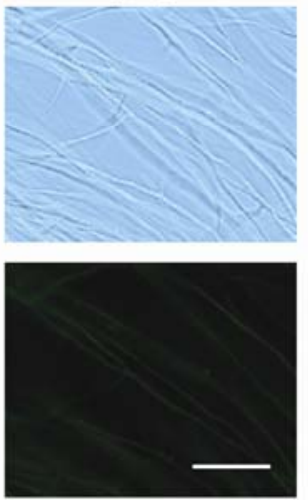

2-2


11
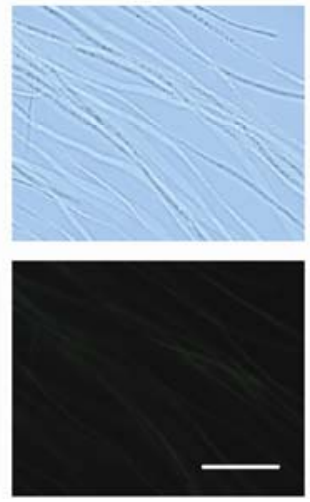

$8-1$
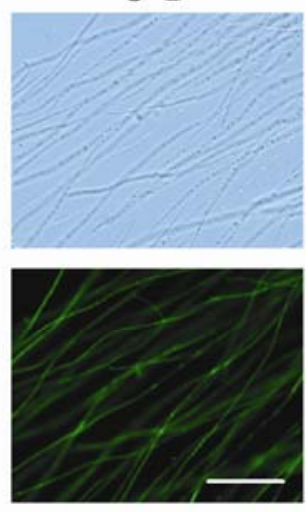

13-2
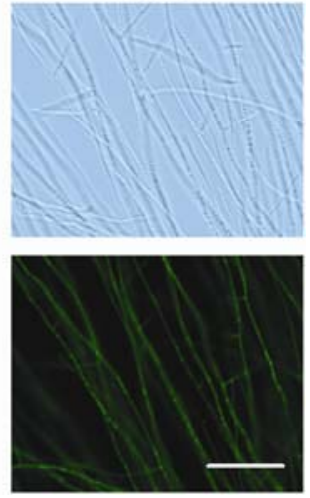

Fig. 5. Images of green fluorescent protein (GFP) fluorescence in mycelia of silenced and nonsilenced transformants of the G1 mutant overexpressing GFP. Green fluorescence of the G1 mutant and transformants were detected in germinating spores on agar plates. Green fluorescence was detected with an Olympus BX51 microscope with a B excitation. Upper panel of each transformant shows the view under light microscope, and the lower panel shows the same view under fluorescence. All experiments were repeated at least three times with similar results. Scale bars represent $50 \mu \mathrm{m}$. 
two (2-1 and 2-2) transformants that lost GFP florescence altogether. Compared with that observed for GFP RNAi, approximately the same percentage of transformants lost or had strongly reduced transcript accumulation of ACTT2, ACT-toxin production, and pathogenicity when the A. alternata tangerine pathotype was transformed with the vector construct designed to generate a hairpin ACTT2 RNA. Transformation constructs giving hairpin structure of RNA using sense and antisense sequence of the target gene with an intron sequence-based hairpin head spacer are known as an effective and relatively stable way for RNA silencing in fungi as well as many other organisms (Cogoni and Macino 1999; Hannon 2003; Kadotani et al. 2003; Liu et al. 2002). This is likely due to recognition of such dsRNA as aberrant RNA by RNA-dependent RNA polymerasemediated process (Baulcombe 1996). In this study, RNAsilenced A. alternata transformants showed similar or greater expression reduction compared with other reports for filamentous fungi (Cogoni et al. 1996; Fitzgerald et al. 2004; Hammond and Keller 2005; Kadotani et al. 2003; Moriwaki et al. 2007; Mouyna et al. 2004; Nakayashiki et al. 2005; Romano and Macino 1992; Yamada et al. 2007). The low frequency $(2.5 \%)$ of completely silenced strains recovered in this study might be related to copy number of the target genes. The frequency of completely silenced strains of other HST biosynthesis genes with lower copy number in other pathotypes of $A$. alternata was greater than the frequency recovered for silencing of ACTT2 in this study (unpublished data).

ACTT2 is thought to play a role in the biosynthesis of the common decatrienoic acid backbone of ACT, AK, and AF toxins, and sequence similarities of ACTT2 orthologs among these three pathotypes are high. ACTT2 (accession AB432914) and AKT2 (accession AB015352) are 90.6\% similar and ACTT2 and AFT2 (AB434468) are also 90.6\% similar. A complication
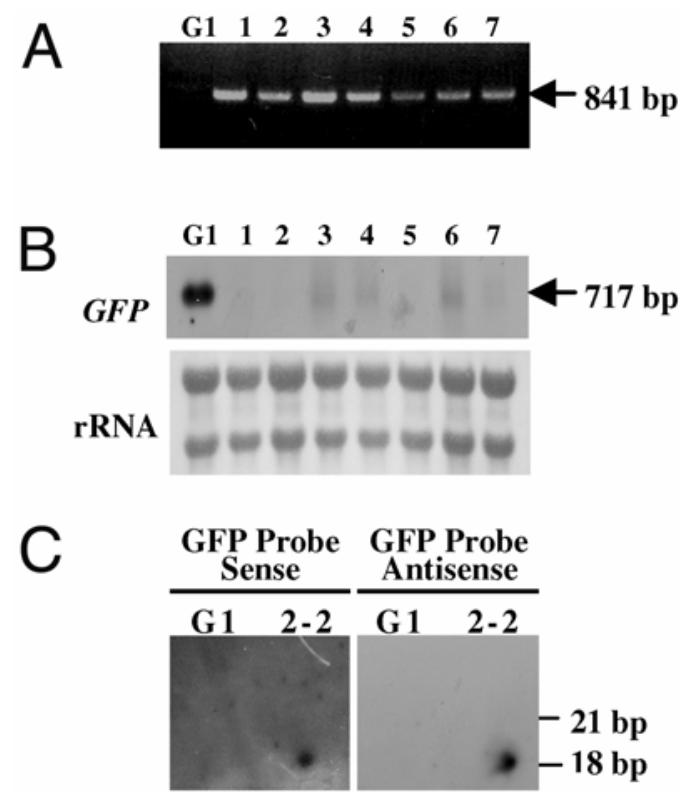

Fig. 6. RNA-silencing transformants for green fluorescent protein (GFP) expression in the GFP-overexpressing strain. A, Confirmation of insertion of GFP-silencing vector to the silenced transformants using polymerase chain reaction. Lane G1 =G1 mutant, lane $1=$ strain $2-1$, lane $2=$ strain 2-2, lane $3=$ strain $8-1$, lane $4=$ strain $9-1$, lane $5=$ strain $9-2$, lane $6=$ strain 13-2, and lane $7=$ strain 11 . B, Northern blot analysis of the accumulation of GFP mRNA in the silenced transformants. The rRNA, strained with methylene blue and photographed before blotting, is shown below the blot. $\mathbf{C}$, Small interfering RNAs of GFP were also detected by Northen blot. Total RNA was separated on a $15 \%$ polyacrylamide gel and was hybridized with digoxigenin-labeled sense and antisense GFP RNA probes. for comparative analysis of these genes is that they are duplicated in the genome. There are multiple copies of this gene carried on the 1.9-Mb chromosome of A. alternata tangerine pathotype strain $\mathrm{SH} 20$, and sequence identity among copies is high. For example, the sequence identity of ACTT2 and ACTT2-1 (accession AB432915) is 98.8\%. Homologs of ACTT2 identified from a dual toxin-producing strain of A. alternata (BC3-5-1-OS2A) (Masunaka et al. 2005) also showed similarities of 99 and $98.9 \%$ for ACTT2-2 (accession AB432916) and ACTT2-3 (accession AB432917), respectively. Although conventional disruption of ACTT2 could not be accomplished due to the high number of the copies identified in the genome, the high sequence identity among these copies of ACTT2 is likely an advantage for RNA silencing, because it allows knockdown of all copies of this gene simultaneously. Target sequences of RISC among respective ACTT2 copies are likely to have high identities, and the RISC recognizes them as the target for silencing without selecting the source of original DNA copies. Since the target recognition process is highly sequence-specific but does not always require $100 \%$ identity (Elbashir et al. 2001), sequence identity among functional copies of ACTT2 is likely high enough to be recognized by ACTT2 siRNA-ori-


Fig. 7. Transformation and expression of a plasmid construct expressing hairpin ACTT2 RNAs, reduced ACTT2 transcripts, ACT-toxin production, as well as pathogenicity. A, Confirmation of insertion of ACTT2-silencing vector into silenced transformants using polymerase chain reaction (PCR). Lane $\mathrm{W}=$ wild-type strain SH20, lane $1=$ strain S-7-3, and lane $2=$ strain S-7-24-2. B, Reverse transcription-PCR detection of ACTT2 transcripts in wild-type SH20 (WT) and the silenced transformants S-7-3 (1), and S-724-2 (2). C, High-pressure liquid chromatography charts of each extract from culture filtrates from the wild type SH20 (WT) and silenced transformants S-7-3 (1) and S-7-24-2 (2). D, Citrus leaves were spray-inoculated with conidia of wild type SH20 (WT) and silenced transformants S-7-3 (1) and S-7-24-2 (2). 
ented RISC. Indeed, we obtained a transformant (S-7-24-2) that did not produce ACT toxin because of lack of ACTT2 transcript by this method, thus demonstrating the role of ACTT2 in the biosynthesis of ACT toxin and importance of the toxin in pathogenicity. To our knowledge, this is the first documented case of RNA silencing used to disrupt production of a hostspecific toxin in a filamentous fungus. RNA silencing was used to suppress mycotoxin production and virulence of $F$. graminearum (McDonald et al. 2005). Our results indicate that RNA silencing using vectors that generate hairpin RNA of the target gene will be useful for functional analysis of HST genes in other pathotypes of A. alternata as well as HST produced by other filamentous fungi.

\section{MATERIALS AND METHODS}

\section{Plants and fungal strains.}

Young citrus leaves (midrib length 2 to $4 \mathrm{~cm}$ ) of cultivar Iyokan tangor (Citrus iyo hort. Ex Tanaka) were produced in the greenhouse as described previously and used for inoculation and toxin sensitivity assays (Masunaka et al. 2000). Iyokan is susceptible to the tangerine pathotype of A. alternata and sensitive to ACT toxin (Kohmoto et al. 1991).

Strains of the tangerine pathotype of A. alternata were obtained from leaf lesions of Minneola tangelo (Citrus reticulata Blanco $\times$ Citrus paradisi Macf.) and rough lemon in Florida for a study of the population structure and host specificity of the Alternaria brown spot pathogen (Peever et al. 1999; Masunaka et al. 2000, 2005). Isolates SH11, SH12, SH14, SH15, SH18, SH19, SH20, SH21 and EV10, EV13, and EV14 are tangerine pathotype isolates, whereas isolates $\mathrm{HC} 1, \mathrm{HC} 7, \mathrm{HC} 8, \mathrm{BC} 19$, and $\mathrm{BC} 27$ are rough lemon pathotype isolates (Peever et al. 1999; Masunaka et al. 2000, 2005). Tangerine pathotype SH20 has been used previously as a reference strain for the brown spot pathogen (Masunaka et al. 2000). Isolates $\mathrm{HC} 14$ and $\mathrm{BC} 17$ are nonpathogenic isolates of A. alternata recovered from rough lemon leaves (Peever et al. 1999; Masunaka et al. 2000, 2005). In addition, laboratory stock strains of saprophytic A. alternata (isolates O-94 and IFO031189) (Tanaka et al. 1999) and a citrus black rot strain (G1) (ATCC58171) (Isshiki et al. 2001, 2003) were used in this study. A GFP-expressing mutant of G1 (Isshiki et al. 2003) was previously generated by introducing the GFP gene into wild-type black rot isolate ATCC58171. All isolates including transformants for RNA silencing of GFP and ACTT2 were stored in $25 \%$ (vol/vol) glycerol at $-85^{\circ} \mathrm{C}$, and cultures were initiated from the stocks for each experiment by growth on V8 juice agar or potato dextrose agar (PDA) plates.

\section{Nucleic acid manipulations.}

Genomic DNA and total RNA were isolated from mycelium of wild type or mutants grown at $24^{\circ} \mathrm{C}$ for 21 to 25 days in potato dextrose broth (PDB) (for GFP-related studies) or AC medium (for analyzing ACTT2-silencing mutants), as described previously (Masunaka et al. 2000; Isshiki et al. 2001). Restriction enzyme digestion of genomic DNA ( $5 \mu \mathrm{g})$, agarose gel electrophoresis and transfer to Hybond $\mathrm{N}^{+}$membrane (Amersham Biosciences, Piscataway, NJ, U.S.A.) by capillary transfer were conducted under standard conditions (Sambrook et al. 1989). PCR probes for Southern blots were prepared using the PCR DIG probe synthesis kit (Roche, Mannheim, Germany), with respective primer sets, following the manufacturer's instructions. Genomic Southern hybridization following various restriction-enzyme digestions was performed at $68^{\circ} \mathrm{C}$ overnight with digoxigenin (DIG)-labeled ACTT2 probe prepared by the primer set of ACTT2F1 (5'-ATGCAGCAGCCCA
TCATT-3') and ACTT2R1 (5'-ACATATCGACAGGGCCTGT$3^{\prime}$ ) for ACTT2 detection by the method described previously (Masunaka et al. 2000) and with DIG-labeled GFP probe prepared by the primer set of GFPF1 (5'-ATGGTGAGCAAGGG CGA-3') and GFPR1 (5'-TTACTTGTACAGCTCGT-3') for GFP detection by the method described previously (Isshiki et al. 2003).

For Northern blots, total RNA ( $8 \mu \mathrm{g}$ per lane) was loaded on agarose-formaldehyde gels and was transferred to Hybond $\mathrm{N}^{+}$ membrane by capillary transfer (Sambrook et al. 1989). Ribosomal RNAs on the membrane were stained with $0.02 \%$ (wt/ vol) methylene blue to confirm equal RNA loading (Sambrook et al. 1989). Hybridization for GFP mRNA detection was performed at $50^{\circ} \mathrm{C}$ overnight with DIG-labeled GFP PCR probe.

Small RNAs were extracted and detected using methods described by Dalmay and associates (2000), with minor modifications. The DIG-labeled GFP RNA probe was prepared by in vitro transcription and labeling, using the DIG RNA labeling kit (Roche), from PCR products amplified using GFPF1 (5'ATGGTGAGCAAGGGCGA-3') and GFPR1 (5'-TTACTTG TACAGCTCGT-3') (Isshiki et al. 2003) in the pSPT18 vector (included in the kit), following the manufacturer's instructions. Hybridization was performed at $68^{\circ} \mathrm{C}$ overnight with each probe $(100 \mathrm{ng} / \mathrm{ml})$. Detection was performed under the same conditions as the Southern and Northern blot analyses described above.

For RT-PCR, isolation of total RNA from mycelia and cycling conditions were carried out as previously described (Masunaka et al. 2000), and ACTT2 transcripts were amplified using the same primer sets as used for synthesis of DIGlabeled ACTT2 probe prepared with primers of ACTT2F1 and ACTT2R1. RT-PCR products were run on agarose gels and were transferred to Hybond $\mathrm{N}^{+}$membrane using standard methods (Sambrook et al. 1989), and were detected with the DIG-labeled ACTT2 probe as described above.

Insertions of RNA-silencing vector constructs were confirmed by genomic PCR using the primer set of PacCITF1multisite (5'-GAATTCTGCAGATATCAGATCTGTAAGTTGACC GCCAAG-3') designed from the spacer region in the internal vector construct and ACTT2R1 for pASYII-ACCT2 vector construct and PacCITF1multisite and GFPR1 for pASY-GFP vector construct.

\section{PFGE and hybridization.}

Preparation of chromosomes from fungal protoplasts and PFGE were carried out according to the methods described previously (Hatta et al. 2002; Masunaka et al. 2005). Running conditions (duration, voltage, linear gradient of switching time) in the PFGE apparatus (CHEF-DRII, BioRad, Hercules, CA, U.S.A.) consisted of $0.5 \times$ tris-borate-EDTA (Sambrook et al. 1989) at $8^{\circ} \mathrm{C}$ in $0.8 \%$ (wt/vol) agarose gel (Seakem Gold agarose; Cambrex BioScience Rockland, Inc., Rockland, ME, U.S.A.), 13:5.4:120 h/V cm${ }^{-1} / \mathrm{s}, 13: 5.4: 180$ $\mathrm{h} / \mathrm{V} \mathrm{cm}-1 / \mathrm{s}$. Chromosomal DNA bands were visualized by ethidium bromide staining, and the gel was nicked with 0.2 $\mathrm{N} \mathrm{HCl}$ for 20 min and was soaked in $0.4 \mathrm{~N} \mathrm{NaOH}$ plus $1.5 \mathrm{M}$ $\mathrm{NaCl}$ for 30 min to transfer Hybond $\mathrm{N}^{+}$membranes by alkaline capillary transfer (Sambrook et al. 1989) with $0.4 \mathrm{~N}$ $\mathrm{NaOH}$ and $1.5 \mathrm{M} \mathrm{NaCl}$ for $48 \mathrm{~h}$. The membrane was baked at $80^{\circ} \mathrm{C}$ for $2 \mathrm{~h}$ to fix the DNA, was washed twice with sterile water at room temperature for 5 min with $0.2 \mathrm{~N} \mathrm{NaOH}$ plus $1 \%$ (vol/vol) sodium dodecyl sulfate at $50^{\circ} \mathrm{C}$ for $20 \mathrm{~min}$, and was hybridized at $68^{\circ} \mathrm{C}$ for $30 \mathrm{~min}$ with the same ACTT2 probes used for the Southern blot analysis described above. Hybridization and washing were conducted under high stringency conditions, according to methods described previously (Hatta et al. 2002; Masunaka et al. 2005). 


\section{Plasmid constructs.}

Plasmid vectors pASY and pASY-II (Fig. 4) were constructed from Alternaria overexpression vector pAOEIK (Katoh et al. 2007) for use as RNA silencing vectors in Alternaria spp. For construction of pASY, the intron region ( $97 \mathrm{bp}$ ) of AcPacC (accession AB433595), a pH-dependent regulatory gene of $A$. alternata, was amplified and added as the spacer sequence in the vector, for construction of a part of the hairpin head of dsRNA. The spacer region forming a hairpin head was amplified from genomic DNA of A. alternata tangerine pathotype strain $\mathrm{SH} 20$ by PCR consisting of 30 cycles of denaturing for $30 \mathrm{~s}$ at $95^{\circ} \mathrm{C}$, primer annealing for $30 \mathrm{~s}$ at $50^{\circ} \mathrm{C}$, and extension for $15 \mathrm{~s}$ at $72^{\circ} \mathrm{C}$. The forward primer of PacCITF1multisite (5'-GAATTCTGCAGATATCAGATCTGTAAGTTGACCGCC AAG-3') contained EcoRI, PstI, EcoRV, and BglII sites in the primer sequence, and the reverse primer PacCITR1multisite (5'-GAATTCAAGCTTTAAATTCGAACTGCAATCGAGTC AGC-3') contained EcoRI, HindIII, DraI, and $N s p \mathrm{~V}$ sites in the sequence. Both the PCR product (AB433596) and pAOEIK (Katoh et al. 2007) were digested with EcoRI, and the EcoRI-digested pAOEIK, following dephosphorylation with alkaline phosphatase (Takara, Shiga, Japan), was ligated with the PCR product at the region between the promoter and terminator sequences of Aspergillus nidulans trpC (Fig. 4). For construction of pASY-II, a cassette containing the NPTII gene, which confers geneticin resistance, under the $\operatorname{trp} C$ promoter and terminator regulation was digested by SacI and NotI from the plasmid vector pII99 (Namiki et al. 2001) and was ligated into the predigested pASY with the same restriction enzymes (Fig. 4). Insertions and direction of the PCR products were confirmed by sequencing with the dideoxy chain termination method (Sanger et al. 1977), using an ABI PRISM dye termination cycle sequencing ready reaction kit (Applied Biosystems, Foster City, CA, U.S.A.) and an automated fluorescent DNA sequencer (Model 310; Applied Biosystems).

The entire ORF of GFP was amplified from pTEFEGFP (Van den Wymelenberg et al. 1997) by PCR consisting of 30 cycles of denaturing for $1 \mathrm{~min}$ at $95^{\circ} \mathrm{C}$, primer annealing for $1 \mathrm{~min}$ at $48^{\circ} \mathrm{C}$, and extension for $1 \mathrm{~min}$ at $72^{\circ} \mathrm{C}$, using a primer set of either GFPF1NspV (5'-TTCGAAATGGTGAGCAAGGGCGA$3^{\prime}$ ), containing a $N s p \mathrm{~V}$ site, and GFPR1HindIII (5'-CCCAAG CTTGGGTTACTTGTACAGCTCGT-3'), containing a HindIII site, or GFP F1BgIII (5'-GAAGATCTTCATGGTGAGCAAGG GCGA-3'), containing a $B g l$ II site, and GFPR1EcoRV (5'-GA TATCTTACTTGTACAGCTCGT-3'), containing a EcoRV site. Amplicons were subcloned into pASY to construct the RNAsilencing vector pASY-GFP with the following procedures. The pASY vector was first digested with $B g l \mathrm{II}$ and $E c o \mathrm{RV}$, and then, the PCR product was amplified with GFPF1BglII, and GFPR1EcoRV was subcloned after digestion with BglII and EcoRV (Fig. 4). The vector (Fig. 4) was redigested with $N s p \mathrm{~V}$ and HindIII, and the PCR product was amplified with GFPF1$N s p \mathrm{~V}$, and GFPR1HindIII was subcloned into the vector after digestion with $N s p \mathrm{~V}$ and HindIII. Insertions of the first PCR product between the $\operatorname{trp} C$ promoter and spacer region as well as the second PCR product between the spacer region and $\operatorname{trp} C$ terminator (Fig. 4) were confirmed by sequencing as described above.

For construction of the ACTT2 RNA-silencing vector, inserts of ACTT2 were amplified from subcloned ACTT2 cDNA by PCR consisting of 30 cycles (denaturing for $1 \mathrm{~min}$ at $95^{\circ} \mathrm{C}$, primer annealing for $1 \mathrm{~min}$ at $50^{\circ} \mathrm{C}$, and extension for $1 \mathrm{~min}$ at $\left.72^{\circ} \mathrm{C}\right)$, using a primer set of either ACTT2F1BglII $\left(5^{\prime}\right.$-GAAG ATCTTCATGCAGCAGCCCATCATT-3'), containing a $B g l$ II site, and ACTT2R1BgIII (5'-GAAGATCTTCCGACTGCAGA TATTTCATCC-3'), containing a BglII site, or ACTT2F1NspV (5'-TTCGAAATGCAGCAGCCCATCATT-3'), contain- ing a $N s p \mathrm{~V}$ site, and ACTT2R1HindIII (5'-AAGCTTCGAC TGCAGATATTTCATCC-3'), containing a HindIII site. Both the PCR product, amplified with ACTT2F1BglII and ACTT2R1BglII, and pASY-II were digested with $B g l I I$, and the $B g l$ IIdigested pASY-II, following dephosphorylation with alkaline phosphatase (Takara), was ligated with the PCR product at the region between the $\operatorname{trpC}$ promoter and the spacer region (Fig. 4). The vector was redigested with $N s p \mathrm{~V}$ and HindIII, and the PCR product was amplified with ACTT2F1NspV, and ACTT2R1HindIII was subcloned into the vector after digestion with $N s p \mathrm{~V}$ and HindIII at the region between the spacer region and $\operatorname{trpC}$ terminator (Fig. 4). Insertions and direction of respective PCR products were confirmed by sequencing as described above.

\section{Fungal transformation.}

Transformation to Alternaria spp. was carried out using methods described previously (Isshiki et al. 2001, 2003). Protoplasts $\left(1 \times 10^{7}\right)$ of mutant G1 (Isshiki et al. 2003) were transformed with $3 \mu \mathrm{g}$ each of the vector pASY-GFP and pII99 carrying NPTII cassette as the selection marker (Namiki et al. 2001). Protoplasts $\left(1 \times 10^{7}\right)$ of strain $\mathrm{SH} 20$ were transformed with $3 \mu \mathrm{g}$ of the vector pASYII-ACTT2 carrying a NPTII cassette as the selectable marker. Transformants were selected on PDA plates containing geneticin $(200 \mu \mathrm{g} / \mathrm{ml})$ by growth at $24^{\circ} \mathrm{C}$ for 5 to 7 days, and single-spore cultures were recovered as previously described (Isshiki et al. 2001; 2003).

\section{Determination of GFP florescence, ACT-toxin production, and pathogenicity of RNA-silencing transformants.}

GFP expressed in transformants was detected using an Olympus BX51 microscope (Olympus, Tokyo) with a B excitation filter (460 to $480 \mathrm{~nm}$ ). Relative intensity of green fluorescence from germinating spores of transformants in PDB after $24 \mathrm{~h}$ of incubation at $24^{\circ} \mathrm{C}$ with $120 \mathrm{rpm}$ shaking was estimated against that of the G1 mutant (Isshiki et al. 2003), using the Image Gauge program version 4.0 (Fuji Photo Film, Tokyo) following the manufacturer's instructions. Same microscopic view was also observed under light microscope by differential interference contrast with U-DICT in the Olympus BX51 microscope. Three different fields were observed independently for each treatment, and an average of the relative present rate of intensity was obtained.

ACT-toxin production was estimated by placing diluted culture filtrates $\left(10^{1}\right.$ to $10^{3}$ in water) onto wounded sites of young leaves of Iyokan and Nijisseiki, as previously described (Masunaka et al. 2000). Seventy-five ACTT2-silenced transformants were tested. Leaves were incubated in a moist chamber at $24^{\circ} \mathrm{C}$ in the dark, and necrosis development on the leaves was observed after $48 \mathrm{~h}$. Transformants causing less than $50 \%$ necrosis compared with the wild type (strain $\mathrm{SH} 20$ ) were further examined for pathogenicity in a plant inoculation assay, and ACT-toxin production was assessed by HPLC.

Production of ACT toxin in culture filtrates was determined by HPLC. A. alternata $\mathrm{SH} 20$ and its mutants were grown in 200-ml flasks containing $50 \mathrm{ml}$ of AC-toxin medium (Kohmoto et al. 1979,1993 ) for 25 to 30 days at $24^{\circ} \mathrm{C}$. Culture filtrates were adsorbed to Amberlite XAD2, extracted with methanol, extracted twice with ethyl acetate, and suspended in methanol (Kohmoto et al. 1993). The methanol phase was passed through a Sep-Pak Column Plus C18 cartridge (Waters, Milford, MA, U.S.A.) and were further analyzed by bioassay and HPLC (Model PU-2080; Japan Spectroscopic, Tokyo), with an absorbance at $290 \mathrm{~nm}$, using a Develosil ODS-5 column $(4.6 \times$ $250 \mathrm{~mm}$, Nomura Chemical, Nagoya, Japan) with a gradient solvent system composed of acetonitrile, water, and acetic acid 
(linear gradient from 30:70:1 to $60: 40: 1, \mathrm{vol} / \mathrm{vol} / \mathrm{vol}$ ) for 30 min at a flow rate of $1 \mathrm{ml} / \mathrm{min}$ (Kohmoto et al. 1993). Relative comparison of ACT toxin peak areas was carried out using a chromatographyic analysis program JASCO-Borwin (version 1.50, Japan Spectroscopic) according to the manufacturer's instructions.

Pathogenicity was determined by spots and necrosis development on leaves spray-inoculated with conidia of A. alternata SH20 and its RNA-silenced mutants as previously described (Kohmoto et al. 1993). Conidia of each isolate were collected and suspended in water at a concentration of $1 \times 10^{5}$ spores per milliliter and were spray-inoculated onto detached, young leaves (midrib length 3 to $4 \mathrm{~cm}$ ) of ACT toxin-sensitive citrus cultivar Iyokan as previously described (Masunaka et al. 2000, 2005). Inoculated leaves were incubated in a moist chamber for $48 \mathrm{~h}$ at $24^{\circ} \mathrm{C}$ in the dark, and the development of leaf spots and necrosis was observed.

\section{ACKNOWLEDGMENTS}

We thank L. W. Timmer for continuous support of this project and for providing all Florida strains of A. alternata and M. Kodama and H. Otani, Tottori University, for valuable discussions and providing strain O-94. We also thank D. Cullen, A. Van den Wymelenberg, and J. Andrews, University of Wisconsin, for providing pTEFEGFP containing GFP. This work was supported by grants for scientific research on priority area A from the Ministry of Education, Culture, Sports, Science, and Technology of Japan, Precursory Research for Embryonic Science and Technology from the Japan Science and Technology Agency, Special Coordination Funds for Promoting Sciences from the Ministry of Education, Culture, Sports, Science, and Technology of Japan.

\section{LITERATURE CITED}

Akimitsu, K., Peever, T. L., and Timmer, L. W. 2003. Molecular, ecological and evolutionary approaches to understanding Alternaria diseases of citrus. Mol. Plant Pathol. 4:435-446.

Baulcombe, D. C. 1996. RNA as a target and an initiator of post-transcriptional gene silencing in transgenic plants. Plant Mol. Biol. 32:7988.

Bernstein, E., Caudy, A. A., Hammond, S. M., and Hannon, G. J. 2001. Role for a bidentate ribonuclease in the initiation step of RNA interference. Nature 409:363-366.

Cogoni, C., and Macino, G. 1999. Gene silencing in Neurospora crassa requires a protein homologous to RNA-dependent RNA polymerase. Nature 399:166-169.

Cogoni, C., Irelan, J., Schumacher, M., Schmidhause, T. J., Selker, E. U., and Macino, G. 1996. Transgene silencing of the al-1 gene in vegetative cells of Neurospora is mediated by a cytoplasmic effector and does not depend on DNA-DNA interactions or DNA methylation. EMBO (Eur. Mol. Biol. Organ.) J. 15:3153-3163.

Dalmay, T., Hamilton, A., Rudd, S., Angell, S., and Baulcombe, D. C. 2000. An RNA-dependent RNA polymerase gene in Arabidopsis is required for posttranscriptional gene silencing mediated by a transgene but not by a virus. Cell 26:543-553.

Elbashir, S. M., Lendeckel, W., and Tuschl, T. 2001. RNA interference is mediated by 21- and 22- nucleotide RNAs. Genes Dev. 15:188-200.

Fire, A., Xu, S., Montgomery, M. K., Kostas, S. A., Driver, S. E., and Mello, C. C. 1998. Potent and specific genetic interference by doublestranded RNA in Caenorhabditis elegans. Nature 391:806-811.

Fitzgerald, A., van Kan, J. A. L., and Plummer, K. M. 2004. Simultaneous silencing of multiple genes in the apple scab fungus, Venturia inaequalis, by expression of RNA with chimeric inverted repeats. Fungal Genet. Biol. 41:964-971.

Hammond, T. M., and Keller, N. P. 2005. RNA silencing in Aspergillus nidulans is independent of RNA-dependent RNA polymerases. Genetics 169:607-617.

Hammond, S. M., Caudy, A. A., and Hannon, G. J. 2001. Post-transcriptional gene silencing by double stranded RNA. Nat. Rev. 2:100-119.

Hannon, G. J. 2003. RNAi: A guide to gene silencing. Cold Spring Harbor Laboratory Press, Cold Spring Harbor, NY, U.S.A.

Hatta, R., Ito, K., Hosaki, Y., Tanaka, T., Tanaka, A., Yamamoto, M., Akimitsu, K., and Tsuge, K. 2002. A conditionally dispensable chromosome controls host-specific pathogenicity in the fungal plant pathogen Alternaria alternata. Genetics 161:59-70.
Isshiki, A., Akimitsu, K., Yamamoto, M., and Yamamoto H. 2001. Endopolygalacturonase is essential for citrus black rot caused by Alternaria citri but not brown spot caused by Alternaria alternata. Mol. PlantMicrobe Interact. 14:749-757.

Isshiki, A., Ohtani, K., Kyo, M., Yamamoto, H., and Akimitsu, K. 2003. Green fluorescent detection of fungal colonization and endopolygalacturonase gene expression in the interaction of Alternaria citri with citrus. Phytopathology 93:768-773.

Kadotani, N., Nakayashiki, H., Tosa, Y., and Mayama, S. 2003. RNA silencing in the phytopathogenic fungus Magnaporthe oryzae. Mol. Plant-Microbe Interact. 16:769-776.

Katoh, H., Nalumpang, S., Yamamoto, H., and Akimitsu, K. 2007. Overexpression of citrus polygalacturonase-inhibiting protein in citrus black rot pathogen Alternaria citri. J. Plant Physiol. 164:527-535.

Kohmoto, K., and Otani, H. 1991. Host recognition by toxigenic plant pathogens. Experientia 47:755-764.

Kohmoto, K., Scheffer, R.P., and Whiteside, J. O. 1979. Host-selective toxins from Alternaria citri. Phytopathology 69:667-671.

Kohmoto, K., Akimitsu, K., and Otani, H. 1991. Correlation of resistance and susceptibility of citrus to Alternaria alternata with sensitivity to host-specific toxins. Phytopathology 81:719-722.

Kohmoto, K., Itoh, Y., Shimomura, N., Kondoh, Y., Otani, H., Kodama, M., Nishimura, S., and Nakatsuka, S. 1993. Isolation and biological activities of two host-specific toxins from the tangerine pathotype of Alternaria alternata. Phytopathology 83:495-502.

Liu, H., Cottrell, T. R. Pierini, L. M., Goldman, W. E., and Doering T. L. 2002. RNA interference in the pathogenic fungus Cryptococcus neoformans. Genetics 160:463-470.

Masunaka, A., Ohtani, K., Peever, T. L., Timmer, L. W., Tsuge, T., Yamamoto, M., Yamamoto, H., and Akimitsu, K. 2005. An isolate that is pathogenic to both tangerines and rough lemon and produces two host-selective toxins, ACT- and ACR-toxins. Phytopathology 95:241247.

Masunaka, A., Tanaka, A., Tsuge, T., Peever, T. L., Timmer, L. W., Yamamoto, M., Yamamoto, H., and Akimitsu, K. 2000. Distribution and characterization of $A K T$ homologs in the tangerine pathotype of Alternaria alternata. Phytopathology 90:762-768.

McDonald, T., Brown, D., Keller, N. P., and Hammond, T. M. 2005. RNA silencing of mycotoxin production in Aspergillus and Fusarium species. Mol. Plant-Microbe Interact. 18:539-545.

Moriwaki, A., Ueno, M., Arase, S., and Kihara, J. 2007. RNA-mediated phytopathogenic fungus Bipolaris oryzae. FEMS (Fed. Eur. Microbiol. Soc.) Microbiol. Lett. 269:85-89.

Mouyna, I., Henry, C., Doering, T. L., and Latge, J. P. 2004. Gene silencing with RNA interference in the human pathogenic fungus Aspergillus fumigatus. FEMS (Fed. Eur. Microbiol. Soc.) Microbiol. Lett. 237:317324.

Nakashima, T., Ueno, T., Fukami, H., Taga, T., Masuda, H., Osaki, K., Otani, H., Kohmoto, K., and Nishimura, S. 1985. Isolation and structure of AK-toxin I and II, host specific phytotoxic metabolites produced by Alternaria alternata Japanese pear pathotype. Agric. Biol. Chem. 49:807-815.

Nakatsuka, S., Ueda, K., Goto, T., Yamamoto, M., Nishimura, S., and Kohmoto, K. 1986. Structure of AF-toxin II, one of the host-specific toxins produced by Alternaria alternata strawberry pathotype. Tetrahedron Lett. 27:2753-2756.

Nakayashiki, H., Hanada, S., Quoc, N. B., Kadotani, N., Tosa, Y., and Mayama, S. 2005. RNA silencing as a tool for exploring gene function in ascomycete fungi. Fungal Genet. Biol. 42: 275-283.

Namiki, F., Matsunaga, M., Okuda, M., Inoue, I., Nishi, K., Fujita, Y., and Tsuge, T. 2001. Mutation of an arginine biosynthesis gene causes reduced pathogenicity in Fusarium oxysporum f. sp. melonis. Mol. Plant-Microbe Interact. 14:580-584.

Nishimura, S., and Kohmoto, K. 1983. Host-specific toxins and chemical structures from Alternaria species. Annu. Rev. Phytopathol. 21:87-116.

Peever, T. L., Canihos, Y., Olsen, L., Ibanez, A., Liu, Y. C., and Timmer, L. W. 1999. Population genetic structure and host specificity of Alternaria spp. causing brown spot of Minneola tangelo and rough lemon in Florida. Phytopathology 89:851-860.

Romano, N., and Macino, G. 1992. Quelling: Transient inactivation of gene expression in Neurospora crassa by transformation with homologous sequence. Mol. Microbiol. 6:3343-3353.

Sambrook, J., Fritsch, E. F., and Maniatis, T. 1989. Molecular Cloning: A Laboratory Manual, 2nd ed. Cold Spring Harbor Laboratory Press, Cold Spring Harbor, NY, U.S.A.

Sanger, F., Nicklen, S., and Couldon, A. R. 1977. DNA sequencing with chain-terminating inhibitors. Proc. Natl. Acad. Sci. U.S.A. 74:5463-5467.

Scheffer, R. P., and Livingston, R. S. 1984. Host-selective toxins and their role in plant diseases. Science 223:17-21.

Tanaka, A., Shiotani, H., Yamamoto, M., and Tsuge, T. 1999. Insertional 
mutagenesis and cloning of the genes required for biosynthesis of the host-specific AK-toxin in the Japanese pear pathotype of Alternaria alternata. Mol. Plant-Microbe Interact. 12:691-702.

van den Wymelenberg, A. J., Cullen, D., Spear, R. N., Schoenike, B., and Andrews, J. H. 1997. Expression of green fluorescent protein in Aureobasidium pullulans and quantification of the fungus on leaf surfaces. BioTechniques 23:686-690.

van West, P., Kamoun, S., van't Klooster, J. W., and Govers, F. 1999. Internuclear gene silencing in Phytophthora infestans. Mol. Cell 3:339-348.

Walton, J. D. 1996. Host-selective toxins: Agents of compatibility. Plant Cell 8:1723-1733.
Wolpert, T. J., Dunkle, L. D., and Ciuffetti, L. M. 2003. Host-selective toxins and avirulence determinants: What's in a name? Annu. Rev. Phytopathol. 40:251-285.

Yamada, O., Ikeda, R., Ohkita, Y., Hayashi, R., Sakamoto, K., and Akita, O. 2007. Gene silencing by RNA interference in the koji mold Aspergillus oryzae. Biosci. Biotechnol. Biochem. 71:138-144.

Yoder, O. C. 1980. Toxins in pathogenesis. Annu. Rev. Phytopathol. 18:103-129.

Zamore, P. D., Tuschl, T., Sharp, P. A., and Bartel, D. P. 2000. RNAi: Double stranded RNA directs the ATP-dependent cleavage of mRNA at 2123 nucleotide intervals. Cell 101:23-33. 